\title{
Expression, purification of a novel alkaline Staphylococcus xylosus lipase acting at high temperature
}

\author{
Ahlem Bouaziz ${ }^{1}$, Habib Horchani ${ }^{*}, 1$, Nadia Ben Salem, Youssef Gargouri, Adel Sayari \\ Laboratoire de Biochimie et de Génie Enzymatique des Lipases, ENIS, BP1173, Sfax 3038, Tunisia
}

\section{A R T I C L E I N F O}

\section{Article history:}

Received 8 November 2010

Received in revised form 9 January 2011

Accepted 2 February 2011

Available online 5 March 2011

\section{Keywords:}

Staphylococcus xylosus lipase

Purification

Sequencing

Thermo-alkaline

Expression

Synthesis

\begin{abstract}
A B S T R A C T
A new Staphylococcus xylosus strain was isolated. The extracellular lipase of S. xylosus (wt-SXL2) was purified to homogeneity from the culture medium. The specific activity of the purified enzyme, measured at $\mathrm{pH} 8.5$ and $55^{\circ} \mathrm{C}$ using tributyrin or olive oil emulsion, reached, respectively, $6300 \mathrm{U} / \mathrm{mg}$ or $2850 \mathrm{U} / \mathrm{mg}$. The sequenced $18 \mathrm{~N}$-terminal amino acid showed a high degree of identity with known staphylococcal lipase sequences.

The gene encoding the mature lipase was cloned and sequenced. The deduced amino acid sequence showed a significant similarity with various staphylococcal lipases. The highest overall identity (98.74\%) was found with S. xylosus lipase (SXL1). The mature part of the lipase was expressed in Escherichia coli. The recombinant lipase was purified by affinity chromatography. The specific activity of the recombinant lipase was 4100 or $1500 \mathrm{U} / \mathrm{mg}$ using tributyrin or olive oil emulsion as substrate, respectively, at pH 8.5 and $55^{\circ} \mathrm{C}$.

The wild type and recombinant lipases presented a quite interesting thermal stability, after an incubation of $60 \mathrm{~min}$ at $55^{\circ} \mathrm{C}$ and they are found to be highly stable at a pH ranging from 4 to 11 . Due to its stability at high temperature and in organic solvent, the wt-SXL2 was used as biocatalyst to synthesise a high added value molecules.
\end{abstract}

(C) 2011 Elsevier B.V. All rights reserved.

\section{Introduction}

Lipases (triacylglycerol acylhydrolases, EC 3.1.1.3) are one of the most important classes of hydrolytic enzymes that catalyse both the hydrolysis and the synthesis of esters. Lipase has a number of unique characteristics, including substrate specificity, stereospecificity, regioselectivity and the ability to catalyse heterogeneous reaction at the interface soluble and insoluble water systems [1]. They are ubiquitous enzymes produced by all biological systems animals, plants and microorganisms. In contrast to animal and plant lipases, extracellular microbial lipases can be produced relatively inexpensively by fermentation and in large quantities [2]. In

Abbreviations: Wt-SXL2, Staphylococcus xylosus lipase 2; SSL, Staphylococcus simulans lipase; SXL1, Staphylococcus xylosus lipase 1; SAL2, Staphylococcus aureus lipase 3; SHL, Staphylococcus hyicus lipase; BSA, bovine serum albumin; EDTA, ethylene diamine tetraacetic acid; EGTA, ethylene glycol-bis ( $\beta$-aminoethyl Ether) N,N,N, $\mathrm{N}^{\prime}-$ tetraacetic acid; NaDC, sodium deoxycholate; NaTDC, sodium taurodeoxycholate; PC, phosphatidylcholine; PCR, polymerase chain reaction; SDS/PAGE, sodium dodecyl sulphate/polyacrylamide gel electrophoresis; $\mathrm{TG}$, triacylglycerol; $\mathrm{TC}_{4}$, tributyrin.

* Corresponding author at: Laboratoire de Biochimie et de Génie Enzymatique des Lipases, ENIS, BPW, 3038/1173 Sfax, Tunisia. Tel.: +216 74675 055; fax: +21674675055.

E-mail address: horchani_habib@yahoo.fr (H. Horchani).

1 They have participated equally to this work. addition to their hydrolytic activity, lipases can also catalyse other reactions such as esterification or interesterification. A particular interest relies on lipases capacity of catalysing such reactions and, consequently, the synthesis of fine compounds used for manufacturing products of high aggregate value, such as the engineering of structured lipids for the biotransformation of oils and fats [3-6]. Each application requires unique properties with respect to specificity, stability, optimal temperature, and pH-dependence [7]. In order to use lipases for hydrolysis, esterification, or other applications, it is essential to produce the purified enzyme at high concentrations and to determine its biochemical properties. Only about $2 \%$ of world's microorganisms have been tested as enzyme sources until 2006, and lipases from different sources have large variations in specific activity, fatty acid specificity, optimal temperature, and $\mathrm{pH}$ [8]. More recently several new lipases have been isolated [9-13]. A number of staphylococci producing lipases have been purified and characterized. Some studies, based on sequence comparison or direct mutagenesis, have attempted to explain the biochemical differences between staphylococcal lipases.

The practical application of staphylococcal lipases may be limited due to relatively lower stabilities and catalytic activities under conditions that characterize industrial processes: high temperature and extreme $\mathrm{pH}$ values. However, recently we have isolated a novel lipase produced by Staphylococcus aureus [14]. This enzyme which is stable at high temperature and alkaline conditions, was used to 
catalyse several esterification reactions such as biopolymers and antioxidants $[15,16]$. As the industrial application may require specific properties of the biocatalysts, there is still an interest in finding new lipases that could create novel applications. Specially thermostable and alkaline lipases show higher resistance to chemical process $[15,16]$.

Here, we conducted an extensive screening to isolate a new thermostable and alkaline lipase produced by a newly isolated Staphylococcus xylosus strain. The lipase was purified to homogeneity and the N-terminal sequence was determined and compared to the known staphylococcal lipases. The part of the gene encoding the mature lipase was also cloned, and sequenced. The gene was sub-cloned for over expression in Escherichia coli BL 21 (DE3) and the produced lipase was purified to homogeneity in one step using immobilized metal affinity chromatography. The biochemical properties of the recombinant lipase were compared to those of the wild type one. Due to its stability at high temperature and in organic solvent, the wt-SXL2 could be used as biocatalyst to synthesise some high value molecules such antioxidants [17], flavour esters, biopolymer and estolide esters.

\section{Experimental}

\subsection{Chemicals}

Isopropyl thio- $\beta$-D-galactopyranoside (IPTG) was purchased from Boehringer. Nickel nitriloacetate was from Invitrogen. Tributyrin (99\%; puriss) and benzamidine were from Fluka (Buchs, Switzerland); sodium deoxycholic acid ( $\mathrm{NaDC}$ ), yeast extract and ethylene diamine tetraacetic acid (EDTA) were from Sigma Chemical (St. Louis, USA); casein peptone was from Merck (Darmstadt, Germany); gum arabic was from Mayaud Baker LTD (Dagenham, United Kingdom); marker proteins and supports of chromatography used for lipases purification: Sephacryl S-200, Mono S-Sepharose and Mono Q-Sepharose gels were from Pharmacia (Uppsala, Sweden); pH-stat was from Metrohm (Switzerland).

\subsection{Strains, media and plasmids}

- E. coli strain DH5 $\alpha$ was used as a cloning host for the gene part encoding the mature lipase. For expression, the E. coli strain BL21 (DE3), which contains the structural gene for T7 RNA polymerase under control of the lac promoter, was used. E. coli strains were grown in Luria-Bertani medium, supplemented with $100 \mu \mathrm{g} / \mathrm{ml}$ ampicillin whenever plasmid maintenance was required.

- S. xylosus was grown in medium containing: $17 \mathrm{~g} / \mathrm{l}$ casein peptone, $5 \mathrm{~g} / \mathrm{l}$ yeast extract, $2.5 \mathrm{~g} / \mathrm{l}$ glucose. The culture was incubated in an orbital shaker (Certomat H/HK, Germany, Melsungen) at $200 \mathrm{rpm}$ at $37^{\circ} \mathrm{C}$ and at an initial $\mathrm{pH}$ of 7.4 .

- The plasmid $\mathrm{pCR}^{\circledR} 4 \mathrm{Blunt}^{\mathrm{TOPO}}{ }^{\circledR}$ (Invitrogen corporation) was used as cloning vector. The plasmid pET-14b (Invitrogen), under the control of the T7 promoter, was used for the over-expression of SXL2. PCR products were purified using Wizard PCR preps DNA Purification System (Promega). All enzymes used in DNA manipulations were bought from Promega. Oligonucleotides were synthesised by GENOME Express (Grenoble, France).

\subsection{Screening of lipolytic micro-organisms}

Initial screening of lipolytic microorganisms from various Tunisian biotopes was carried out on a solid medium containing $1 \%$ olive oil, $1 \%$ nutrient broth, $1 \% \mathrm{NaCl}, 1.5 \mathrm{~g}$ agar and $1 \%$. Rhodamine B. The culture plates were incubated at $37^{\circ} \mathrm{C}$, and colonies giving rise to widespread clearing around them were regarded as putative lipase producers. In order to select the best lipase producer for enzyme purification and characterization, strains were cultured in different liquid medium and lipase activity was determined with a pH stat using olive oil or $\mathrm{TC}_{4}$ as substrates. After extensive screening of lipase producers, only one bacterial colony, isolated from the soil of a conditioning oil seed industry, was retained. The identification of this strain has been kindly determined by Dr. Hafedh Dhouib (Centre de biotechnologie de Sfax, Sfax, Tunisia). Based on the biochemical properties and the morphological aspect, the identification of this microorganism showed $99.7 \%$ of identity to $S$. xylosus.

\subsection{Lipase and phospholipase activities assay}

- The lipase activity was measured titrimetrically at pH 8.5 and $55^{\circ} \mathrm{C}$ with a pH-stat under standard conditions using tributyrin $(0.25 \mathrm{ml})$ in $30 \mathrm{ml}$ of $2.5 \mathrm{mM}$ Tris- $\mathrm{HCl} \mathrm{pH} 8.5,2 \mathrm{mM} \mathrm{CaCl}_{2}, 2 \mathrm{mM}$ $\mathrm{NaDC}$ or olive oil emulsion ( $10 \mathrm{ml}$ of oil emulsion in $20 \mathrm{ml}$ of $\mathrm{H}_{2} \mathrm{O}$ $\mathrm{NaCl}$ pH 8.5, $2 \mathrm{mM} \mathrm{CaCl}_{2}, 2 \mathrm{mM} \mathrm{NaDC}$ ) [18]. When measuring the lipase activity in the absence of $\mathrm{CaCl}_{2}$, EDTA or EGTA was added to the lipolytic system.

- The phospholipase activity was checked titrimetrically at pH 8.5 and $55^{\circ} \mathrm{C}$ with a pH-stat using $0.2 \mathrm{~g}$ of phosphatidyl choline mixed in $30 \mathrm{ml}$ of $150 \mathrm{mM} \mathrm{NaCl}, 7 \mathrm{mM} \mathrm{CaCl}$ and $3 \mathrm{mM} \mathrm{NaTDC}$.

Lipolytic activity was expressed as units. One unit corresponds to $1 \mu \mathrm{mol}$ of fatty acid released per minute.

\subsection{DNA manipulation}

\subsubsection{DNA preparation and transformation procedure}

Staphylococcal DNA was prepared as described previously with slight modifications [19]. S. xylosus strain was cultured on LB medium agar at least for $14 \mathrm{~h}$ at $37^{\circ} \mathrm{C}$. Single colony was used to inoculate $10 \mathrm{ml}$ of $\mathrm{LB}$ and then incubated at $37^{\circ} \mathrm{C}$ for $12 \mathrm{~h}$. Cells were harvested from the broth cultures by centrifugation at $3000 \times g$ for $15 \mathrm{~min}$. The pellet was re-suspended in $0.1 \mathrm{ml}$ of TE buffer (10 mM Tris, $1 \mathrm{mM}$ EDTA, pH 8$)$ with lysozyme $(5 \mathrm{mg} / \mathrm{ml})$ and lysostaphin $(4.5 \mathrm{U} / \mathrm{ml})$. The mixture was incubated for $1 \mathrm{~h}$ at $37^{\circ} \mathrm{C}$. After addition of $0.5 \mathrm{ml}$ of guanidine thiocyanate $(0.5 \mathrm{M})$ and $0.25 \mathrm{ml}$ of ammonium acetate $(7.5 \mathrm{M})$, the mixtures were maintained on ice for $10 \mathrm{~min}$. Chloroform-isoamyl alcohol (24:1) $(0.5 \mathrm{ml})$ was added to the suspension, mixed and centrifuged at $13,000 \times g$ for $10 \mathrm{~min}$ at room temperature. The upper phase was collected and DNA was precipitated by addition of $0.7 \mathrm{ml}$ cold isopropanol and centrifuged for $5 \mathrm{~min}$ at $13,000 \times \mathrm{g}$. The DNA was re-suspended in $0.5 \mathrm{ml}$ of TE. DNA samples were treated with RNAse $(10 \mathrm{mg} / \mathrm{ml})$ at $37^{\circ} \mathrm{C}$ for $30 \mathrm{~min}$. DNA was extracted with an equal volume of chloroform-isoamyl alcohol, vortexed and centrifuged for $5 \mathrm{~min}$ at $11,000 \times \mathrm{g}$. The upper phase was collected and a double volume of $90 \%(\mathrm{v} / \mathrm{v})$ ethanol was added. DNA was pelleted by centrifugation for $10 \mathrm{~min}$ at $11,000 \times \mathrm{g}$. The DNA obtained was resupended in TE. The quality of the DNA was checked by electrophoresis in a $1 \%$ agarose gel containing ethidium bromide.

E. coli was transformed using the $\mathrm{CaCl}_{2}$ method. Cloning enzymes are purchased from Promega, Boehring Manheim, BRL or Pharmacia LKB. Assay conditions were in agreement with supplier recommendations.

\subsubsection{Cloning of the mature lipase gene region}

The gene part encoding the mature lipase was amplified by PCR from genomic DNA of $S$. xylosus with primers, 5'-ATCGAATTCATATGTTAAAAGCGAATCAAGTACAA-3', and 5'-GATCGAATTCGGATCCTTAACTTGCTTTCAATTGTGTT-3'. The primers were predicted from the N-terminal sequence of the purified wt-SXL2 and the C-terminal sequence of Staphylococcus 
simulans lipase [20], respectively. The predicted primers contain the nucleotides corresponding to the EcoRI, BamHI and NdeI sites used to target the gene in the right direction. The $50 \mu l$ PCR mixture contained $50 \mathrm{pmol}$ of both primers, $20 \mathrm{pmol}$ of each deoxynucleoside triphosphate, approximately $1 \mu \mathrm{mol}$ genomic DNA as template, polymerisation buffer, and $5 \mathrm{U}$ Taq polymerase (Amersham Pharmacia biotech). The thermal profile involved 35 cycles of denaturating at $94{ }^{\circ} \mathrm{C}$ for $45 \mathrm{~s}$, primer annealing at $55^{\circ} \mathrm{C}$ for $1 \mathrm{~min}$, and extension at $72^{\circ} \mathrm{C}$ for $2 \mathrm{~min}$ ( $10 \mathrm{~min}$ in the last cycle).

The PCR product ( $1.2 \mathrm{~kb}$ ) was isolated and ligated into the EcoRIlinearised and dephosphorylated $\mathrm{pCR}^{\circledR} 4 \mathrm{Blunt}-\mathrm{TOPO}^{\circledR}$ vector, using the $\mathrm{pCR}^{\circledR} 4 \mathrm{Blunt}-\mathrm{TOPO}{ }^{\circledR}$ blunt, according to the manufacturer's protocol (Invitrogen Corporation). Protoplasts of E. coli DH5 $\alpha$ were transformed with the ligation mixture. The resulting recombinant plasmid was named PSXL2. The presence of the appropriate insert was determined by PCR and by digestion analysis. DNA products were analysed on a standard $1 \%$ agarose gel containing ethidium bromide. DNA sequences were determined using the dideoxynucleotide chain termination method according to a cycle sequencing protocol using thermosequenase (Amersham Pharmacia Biotech).

The sequencing reactions were analysed with the DNA sequencer (Genom express, Grenoble, France). The sequencing was performed three times, using the recombinant vector (pSXL2) from three clones as template with M13-sens primer and the M13-antisens primer (Amersham Pharmacia Biotech).

The nucleotide sequence determined in this study has been deposited in the Gene Bank database under access number: HM536978.

\subsubsection{Construction of the recombinant plasmids}

The recombinant plasmid (pSXL2) was double digested by NdeI/BamHI. The double digestion product was purified and ligated into a previously $\mathrm{NdeI} / \mathrm{BamHI}$ linearised and dephosphorylated pET-14b vector. E. coli DH5 $\alpha$ competent cells were transformed with the constructed pET-14b-SXL2 plasmid. The positive colony with gene inserts in the plasmid was identified by single restriction digestion of the plasmid with EcoRI, followed by agarose gel analysis. The identified positive colony was grown in LB medium containing ampicillin $(100 \mu \mathrm{g} / \mathrm{ml})$, and the plasmid pET-14b-SXL2 was isolated from bacteria cells using a plasmid extraction Kit. The isolated pET-14b-SXL2 plasmid was then used to transform E. coli strain BL21 (DE3) competent cells for expression purposes.

\subsubsection{Expression and production of the recombinant lipase}

The E. coli BL21 (DE3) strains containing the recombinant plasmids were grown at $37^{\circ} \mathrm{C}$ in $50 \mathrm{ml}$ LB medium containing $100 \mu \mathrm{g} / \mathrm{ml}$ ampicillin to an $\mathrm{OD}_{600}$ of 0.6 . The culture was then adjusted to $0.4 \mathrm{mM}$ IPTG (data not shown) and incubation continued at $37^{\circ} \mathrm{C}$ for $14 \mathrm{~h}$. Cells were harvested by centrifugation at $6000 \mathrm{rpm}$ for $10 \mathrm{~min}$ and washed two times with buffer C $(20 \mathrm{mM}$ Tris- $\mathrm{HCl}, \mathrm{pH} 8,50 \mathrm{mM} \mathrm{NaCl}, 20 \mathrm{mM}$ immidazole). The cells collected by centrifugation were resuspended in the buffer $C$ and sonicated with $6 \mathrm{~mm}$ diameter tip, to release intracellular proteins. The cell free extract was centrifuged at $10,000 \mathrm{rpm}$ for $20 \mathrm{~min}$ to remove cell debris and assayed for lipase activity. The culture broth obtained from the first centrifugation step was collected and assayed for secreted or intracellular lipase activity.

\subsection{Procedure of lipases purification}

\subsubsection{Purification of the $r$-SXL2}

As mentioned above, the clear supernatant, obtained after the last step of centrifugation, was mixed with $15 \mathrm{ml}$ of the $\mathrm{Ni}^{2+}$ nitriloacetate (NTA) resin (Qiagen, CA, USA) equilibrated with buffer $C$. The crude extract-NTA mixture was loaded into a chromatographic column and washed with $200 \mathrm{ml}$ buffer C. Lipases were eluted with a linear imidazole gradient ( $200 \mathrm{ml}$ of $20-500 \mathrm{mM}$ in buffer C).

\subsubsection{Purification of the $w t-S X L 2$}

$240 \mathrm{ml}$ of culture medium, obtained after $24 \mathrm{~h}$ of cultivation, was centrifuged for $15 \mathrm{~min}$ at $8500 \mathrm{rpm}$ to remove the cells. The supernatant containing extracellular lipase was used as the crude enzyme preparation.

- Ammonium sulphate precipitation: The cell-free culture supernatant was precipitated using solid ammonium sulphate to $65 \%$ saturation. The pellet obtained after centrifugation $(30 \mathrm{~min}$ at $8500 \mathrm{rpm}$ ) was dissolved in $10 \mathrm{ml}$ of buffer A ( $20 \mathrm{mM}$ sodium acetate $\mathrm{pH} 5.4,20 \mathrm{mM} \mathrm{NaCl}$, and $2 \mathrm{mM}$ benzamidine). Insoluble material was removed by centrifugation at $13,000 \mathrm{rpm}$ during 5 min.

- Heat treatment: The supernatant obtained $(10 \mathrm{ml})$ was incubated at $55^{\circ} \mathrm{C}$ for $15 \mathrm{~min}$. Insoluble material was removed by centrifugation at 13,000 rpm during $5 \mathrm{~min}$.

- Filtration on Sephacryl S-200: The enzyme solution $(10 \mathrm{ml})$ was applied to a Sephacryl S-200 column $(2.5 \mathrm{~cm} \times 150 \mathrm{~cm})$ previously equilibrated in buffer $A$ at a rate of $35 \mathrm{ml} / \mathrm{h}$. The fractions containing the lipase activity (eluted at 1.4 void volume) were pooled.

- Cation exchange chromatography: Active fractions eluted from Sephacryl S-200 column were poured into a Mono SSepharose cation exchanger equilibrated in buffer $A$. The column $(2 \mathrm{~cm} \times 30 \mathrm{~cm})$ was rinsed with $400 \mathrm{ml}$ of the same buffer. No lipase activity was detected in the washing flow. Adsorbed material was eluted with a linear $\mathrm{NaCl}$ gradient $(300 \mathrm{ml}$ of $20-500 \mathrm{mM}$ in buffer A) at a rate of $45 \mathrm{ml} / \mathrm{h}$. The wt-SXL2 activity was eluted between 125 and $310 \mathrm{mM} \mathrm{NaCl}$.

- The fractions containing the lipase activity were pooled, concentrated and washed three times with $(3 \times 100 \mathrm{ml})$ of buffer $\mathrm{B}(25 \mathrm{mM}$ Tris- $\mathrm{HCl}, \mathrm{pH} 8)$ to remove $\mathrm{NaCl}$. The enzyme was finally diluted in $50 \mathrm{ml}$ of buffer B and poured into a Mono QSepharose anion exchanger equilibrated in buffer $B$. The column $(2 \mathrm{~cm} \times 30 \mathrm{~cm})$ was washed with $400 \mathrm{ml}$ of the same buffer. No lipase activity was detected in the washing flow. Adsorbed material was eluted with a linear $\mathrm{NaCl}$ gradient $(100 \mathrm{ml}$ of $20-500 \mathrm{mM}$ in buffer B) at a rate of $45 \mathrm{ml} / \mathrm{h}$. The wt-SXL2 activity was eluted between 175 and $250 \mathrm{mM} \mathrm{NaCl}$.

\subsection{Analytical methods}

- The fractions containing lipase activities (wt-SXL2 or r-SXL2) were analysed by analytical polyacrylamide gel electrophoresis in the presence of sodium dodecyl sulphate (SDS-PAGE) following the method of Laemmli [21].

- The protein concentration was determined as described by Bradford [22] using BSA as standard.

- The N-terminal sequence of purified wt-SXL2 was kindly determined by Pr Hafedh MEJDOUB with automated Edaman's degradation, using an Applied Biosystems Protein Sequencer Procise 492 CLC. Samples for sequencing were electroblotted according to Bergman and Jörnvall [23]. Protein transfer was performed for $1 \mathrm{~h}$ at $1 \mathrm{~mA} / \mathrm{cm}^{2}$ at room temperature.

\subsection{Effect of $\mathrm{pH}$ and temperature on enzyme activity and stability}

- Lipase activity was tested at different pHs (5-9.5) at $55^{\circ} \mathrm{C}$. The $\mathrm{pH}$ stability of the two purified lipases was determined by incubating the enzyme in glycine ( $\mathrm{pH} 3-4)$, sodium acetate ( $\mathrm{pH} \mathrm{5-6),}$ phosphate ( $\mathrm{pH} 7)$, Tris- $\mathrm{HCl}(\mathrm{pH} \mathrm{8-9)}$ and borate $(\mathrm{pH} \mathrm{10-11)} \mathrm{for}$ $24 \mathrm{~h}$ at room temperature. The residual activity was determined, 
after centrifugation, under standard assay method.

- The optimum temperature for the lipase activity was determined by carrying out the enzyme assay at different temperatures $\left(37-60^{\circ} \mathrm{C}\right)$ at $\mathrm{pH} 8.5$. The effect of temperature on lipase stability was determined by incubating the enzyme solution at different temperatures $\left(37-60^{\circ} \mathrm{C}\right)$ for $60 \mathrm{~min}$. The residual activity was determined, after centrifugation, under standard conditions.

\subsection{Esterification reaction}

The wt-SXL2 immobilization was made onto $\mathrm{CaCO}_{3}$ as previously described [30]. The esterification reaction was performed, using immobilized wt-SXL2, in screw-capped flasks. The reaction mixture containing different substrate concentrations and different amount of immobilized lipase was carried out at different temperatures with shaking (200 rpm). Aliquots of the reaction mixture were withdrawn periodically. The residual acid content was assayed by titration with sodium hydroxide $3.5 \mathrm{~g} / \mathrm{l}$ using phenolphthalein as indicator and $2 \mathrm{ml}$ of ethanol as quenching agent. The conversion percentage in ester synthesis was based on the amount of the consumed acid.

\section{Results and discussion}

\subsection{Screening of lipolytic microorganisms}

Screening and isolation of microorganisms for lipase activity is most frequently carried out employing agar plates containing triacylglycerol or Tweens. Lipase catalysed hydrolysis gives rise either to clearing or opacity zones developed around colonies of lipolytic organisms.

An initial screening of 120 strains from various Tunisian biotopes was carried out. Colonies giving rise to widespread clearing around them and were regarded as putative lipase producers. About 20 strains in the first stage were selected for their ability to growth at high temperature $\left(45\right.$ and $\left.55^{\circ} \mathrm{C}\right)$ and alkaline conditions (8-9).

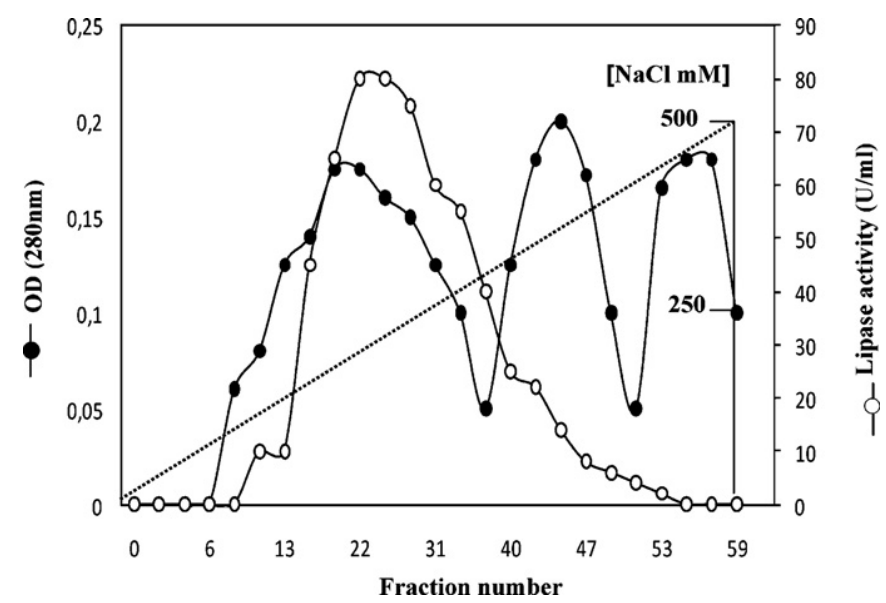

Fig. 1. Chromatographic profile of wt-SXL2 on Mono-S Sepharose. The column $(2 \mathrm{~cm} \times 30 \mathrm{~cm})$ was equilibrated with buffer A. The elution of the adsorbed proteins was then performed with a linear gradient of $\mathrm{NaCl}(20-500 \mathrm{mM})$ at a rate of $45 \mathrm{ml} / \mathrm{h}$. wt-SXL2 activity was eluted between 125 and $310 \mathrm{mM} \mathrm{NaCl}$.

S. xylosus strain was chosen for lipase production since it produced the highest lipase activity $(220 \mathrm{U} / \mathrm{ml})$ at elevated temperature and alkaline conditions. The maximal lipase activity was obtained at the beginning of the stationary phase, after $24 \mathrm{~h}$ of growth in a medium A (data not shown). A decrease in lipase activity was observed during the late stationary phase, probably due to the presence of proteases in the culture medium. The lipase production by S. xylosus $2(220 \mathrm{U} / \mathrm{ml})$ was approximately 8 -fold higher than the one produced by the $S$. xylosus $1(30 \mathrm{U} / \mathrm{ml})$, previously isolated [24]. It is noteworthy that the two strains were cultivated under the same conditions and the activity was measured at the optimal conditions of each lipase using tributyrin as substrate. In addition to the difference in the activity level, the two lipases (SXL1 and SXL2) showed other biochemical differences especially in the temperature and $\mathrm{pH}$ stability.
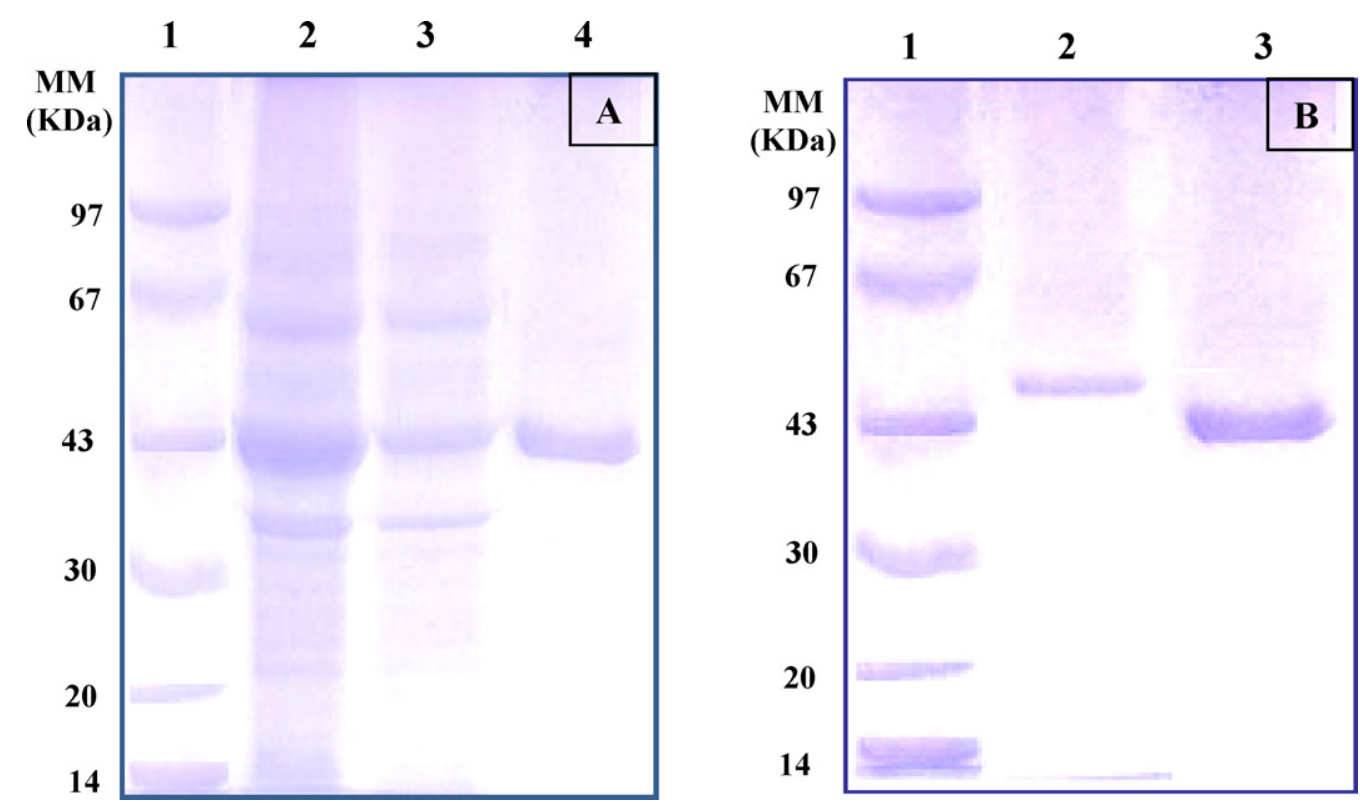

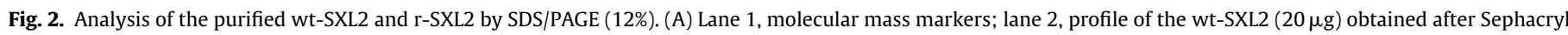

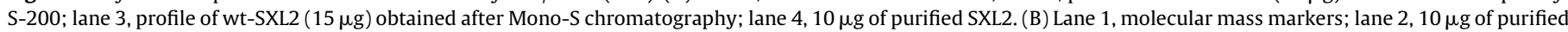
r-SXL2; lane 3, $10 \mu \mathrm{g}$ of purified wt-SXL2. 


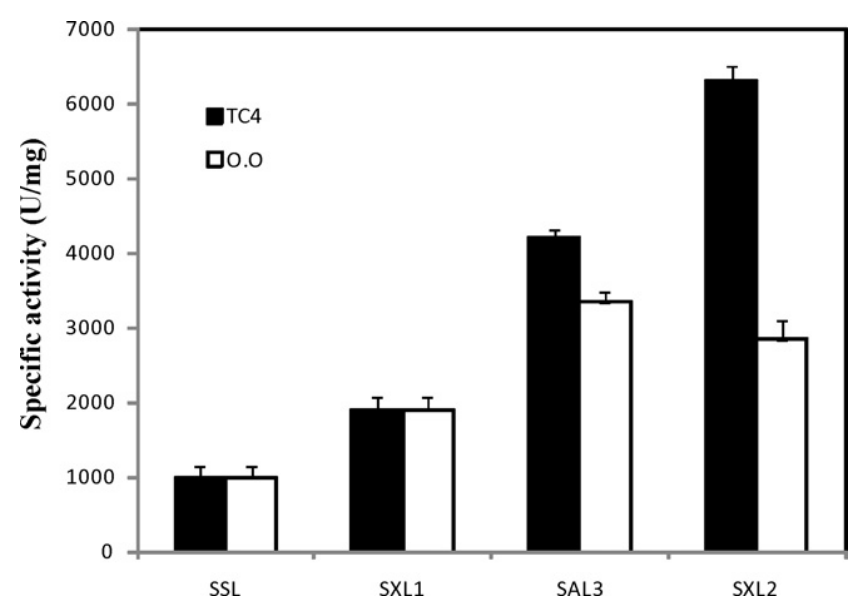

Fig. 3. Specific activities of S. simulans, S. xylosus 1 , S. aureus and S. xylosus 2 lipases using tributyrin or olive oil as substrate. The activities were determined at the standard conditions of each enzyme.

\subsection{Purification of the wt-SXL2}

After $24 \mathrm{~h}$ of culture, the wt-SXL2 was purified according to the procedure described in Section 2. The elution profile of the wtSXL2 obtained after the cation exchange chromatography (Mono-S Sepharose) is shown in Fig. 1. This figure shows that the wt-SXL2 was eluted between 125 and $310 \mathrm{mM} \mathrm{NaCl}$.

The results of the SDS-PAGE analysis of the pooled fractions of the wt-SXL2 and after the last step of chromatography are given in Fig. 2A. This figure shows that the wt-SXL2 exhibited one band corresponding to a molecular mass of about $43 \mathrm{kDa}$.

The purification flow sheet is shown in Table 1 . The specific activity of the pure lipase reached $6300 \mathrm{U} / \mathrm{mg}$ using $\mathrm{TC}_{4}$ as substrate in the presence of $2 \mathrm{mM} \mathrm{CaCl}_{2}, 2 \mathrm{mM} \mathrm{NaDC}$ at $\mathrm{pH} 8.5$ and $55^{\circ} \mathrm{C}$, with a recovery of $11 \%$. Under the same conditions, a specific activity of $2850 \mathrm{U} / \mathrm{mg}$ was obtained when using emulsified olive oil as substrate. The specific activity of the wt-SXL2 on $\mathrm{TC}_{4}$ or olive oil was compared to other purified staphylococcal lipases previously described (Fig. 3). From the data presented in this figure, one can note that, in contrast to SSL and SXL1 which hydrolyse triacylglycerols irrespective of their chain length, the wt-SXL2 has a preference for the short chain substrate $\left(\mathrm{TC}_{4}\right)$. Moreover, the wt-SXL2 is the most active lipase in the staphylococcal family. It presents a specific activity 6-fold and 3-fold higher than the SSL [20] and SXL1 [24], respectively.

It is well known that the SHL, in addition to its hydrolytic activity on triacylglycerols, efficiently hydrolyses phospholipids [25]. In order to test if the wt-SXL2 and the r-SXL2 are able, like SHL, to hydrolyse phospholipids, the purified lipases were incubated with different phospholipids (egg-PC, PG, PE) at different pHs and tem-
Table 2

$\mathrm{N}$-terminal sequence comparison of wt-SXL2 with SSL and SXL1.

\begin{tabular}{ll}
\hline Lipases & Sequence N-terminal \\
\hline SXL2 [present study] & LKANQVQPLNKYPVVFVH \\
SAL3 [14] & LKANQVQPLNKYPVVFVH \\
SSL [20] & ANQVQPLNKYPVVFVHGFLGLVG \\
SXL1 [24] & ANQVQPLNKYPVVFVHGFLGLVG \\
\hline
\end{tabular}

peratures. Our results show that, in contrast to SHL, the two lipases did not present a phospholipase activity on all used phospoholipids (data not shown).

\section{3. $\mathrm{NH}_{2}$-terminal sequence of $w t-S X L 2$}

The $18 \mathrm{NH}_{2}$-terminal amino acids of the wt-SXL2 determined by Edman degradation were: L-K-A-N-Q-V-Q-P-L-N-K-Y-P-V-V-F$\mathrm{V}-\mathrm{H}$. The above mentioned $\mathrm{N}$-terminal sequence of the wt-SXL2 exhibits a high identity with lipases of the same genus previously characterized $[14,20,24]$ (Table 2 ). Two additional amino acid residues (LK) are present at the $\mathrm{N}$ terminus of purified lipase from S. xylosus 2 as compared to SXL1 [24]. The presence of the additional dipeptide Leu-Lys at the N terminus of the wt-SXL2 might originate from a different proteolytic cleavage during processing of the mature enzyme. These residues might be responsible for the differences observed in the biochemical properties of the two lipases. In previous work we have shown that the insertion of two residues (LK) at the N-terminus of the SXL1 was accompanied by an improvement of the temperature action and the stability of the modified enzyme [26].

\subsection{Cloning and sequencing of the mature lipase gene region}

The PCR product corresponding to the gene part encoding the mature SXL2 was cloned and sequenced. It revealed a sequence of 1191 nucleotides (Fig. 4). The deduced polypeptide sequence, corresponding to the mature protein, comprises 397 amino acids with a molecular mass of $43 \mathrm{kDa}$. As revealed by sequence similarity with Staphylococcus hyicus lipases [27], Ser 119, Asp 310 and His 352 are the catalytic triad of SXL2. The amino acid sequence of this mature lipase shows a high identity (98.7\%) with the mature amino acid sequence of SSL [20]. The comparison of the two amino acids sequences shows that the wt-SXL2 is identical to the SSL with the addition of two amino acid residues (LK) at the $\mathrm{N}$ terminus and the substitutions Tyr 39 by Phe, Asn 247 by Asp and Val 311 by Gly.

The lipase expression vector, pET-14b, was constructed by legating the $1191 \mathrm{pb} N d e \mathrm{I} / \mathrm{Bam} \mathrm{HI}$ fragment $\mathrm{pCR}^{\circledR}$ 4Blunt-TOPO ${ }^{\circledR}$ vector into NdeI/BamHI digested pET-14b. This construction places the lipase gene under of a T7 promotor and in frame with N-terminal region coding for six histidines residues, which greatly facilitate the protein purification process.

Table 1

Flow sheets of the wt-SXL2 and the r-SXL2 purification.

\begin{tabular}{|c|c|c|c|c|c|}
\hline Purification step & Total activity (Units) ${ }^{a}$ & Proteins $^{\mathrm{b}}(\mathrm{mg})$ & Specific activity (U/mg) & Activity recovery (\%) & Purification factor \\
\hline \multicolumn{6}{|l|}{ wt-SXL2 } \\
\hline Culture supernatant & 48,000 & 247.42 & 194 & 100 & 1 \\
\hline$\left(\mathrm{NH}_{4}\right)_{2} \mathrm{SO}_{4}$ precipitation & 33,000 & 77.1 & 428 & 69 & 2.2 \\
\hline Heat treatment $\left(15 \mathrm{~min}\right.$ at $\left.55^{\circ} \mathrm{C}\right)$ & 27,000 & 51 & 529 & 57 & 2.72 \\
\hline S-200 chromatography & 16,500 & 18 & 916 & 35 & 4.72 \\
\hline Mono-S chromatography & 7000 & 2.69 & 2600 & 14.6 & 13.4 \\
\hline Mono-Q chromatography & 5300 & 0.85 & 6300 & 11 & 32.5 \\
\hline \multicolumn{6}{|l|}{ r-SXL2 } \\
\hline Culture supernatant & 16,500 & 13.75 & 1200 & 100 & 1 \\
\hline Ni-NTA affinity chromatography & 11,050 & 2.7 & 4100 & 67 & 3.41 \\
\hline
\end{tabular}

a 1 Unit corresponds to $1 \mu \mathrm{mol}$ of fatty acid released per min using tributyrin as substrate.

b Proteins were estimated by the Bradford method [21]. 
(A) cttaaagcgaatcaagtacaaccacttaacaaatatccagttgtttttgtacatggattt 60 $\begin{array}{lllllllllllllllllllll}\mathbf{L} & \mathbf{K} & \mathbf{A} & \mathbf{N} & \mathbf{Q} & \mathbf{V} & \mathbf{Q} & \mathbf{P} & \mathbf{I} & \mathbf{N} & \mathbf{K} & \mathbf{Y} & \mathbf{P} & \mathbf{V} & \mathbf{V} & \mathbf{F} & \mathbf{V} & \mathbf{H} & \mathbf{G} & \mathbf{F} & 20\end{array}$ ttaggattagtaggcgataatgcacctgctttatacccaaattattggggtggaaataaa 120 $\begin{array}{lllllllllllllllllllll}\text { L } & G & \text { L } & \text { V } & \text { G } & \text { D } & \text { N } & \text { A } & \text { P } & \text { A } & \text { L } & \text { Y } & \text { P } & \text { N } & \text { Y } & \text { W } & \text { G } & \text { G } & \text { N } & \text { K } & 40\end{array}$ tataaagttatcgaagaattgagaaagcaaggctataatgtacatcaagcaagtgttagt 180

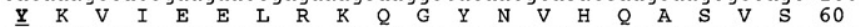
gcatttggtagtaactatgatcgcgctgtagaactttattattacattaaggtggtcgc 240

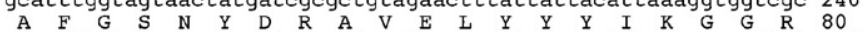
gtagattatggCgCagcacatgCagctaaatacggacatgagcgctatggtaagact tat 300 $\begin{array}{ccccc}\text { V D Y G A A H A A K Y G H E R Y G K T Y } 100 & \end{array}$ aaaggaatcatgcctaattgggaacctggtaaaaggtacatcttgtagggcatagtatg 360

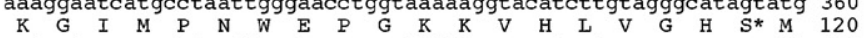
ggtggtcaaacaattcgtttaatggaagagtttttaagaaatggtaacaaagaagaatt 420 $\begin{array}{lllllllllllllllllllll}G & G & Q & T & I & R & L & M & E & E & F & L & R & N & G & N & K & E & E & I & 140\end{array}$ gcctatcataaagcgcatggtggagaaatatcaccattattcactggtggtcataacaat 480

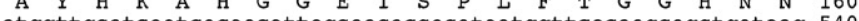
atggttgcatcaatcacaacattagcaacaccacataatggttcacaagcagctgataag 540

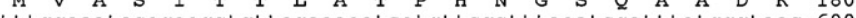
tttggaaatacagaagctgttagaaaatcatgttcgctttaaatcgatttatgggtaac 600 $\begin{array}{lllllllllllllllllllll}\text { F } & \text { G } & \text { N } & T & \text { E } & \text { A } & \text { V } & \text { R } & \text { K } & \text { I } & \text { M } & \text { F } & \text { A } & \text { L } & \text { N } & \text { R } & \text { F } & \text { M } & \text { G } & \text { N } & 200\end{array}$

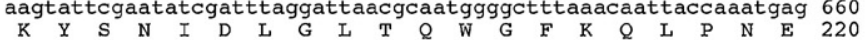
agttacattgactatataaaacgcgttagtaaaagcaaaatttggacatcagacgacaat 720

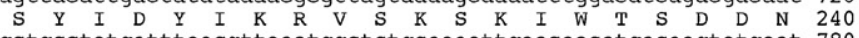

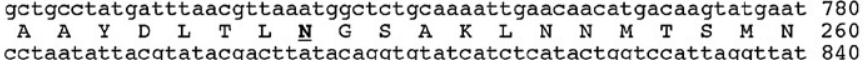

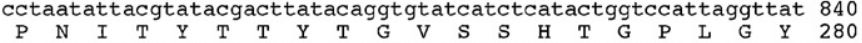
gaaatcctgatttaggtacatttttcttaatggatacaacgagtagaattattggtcat 900 $\begin{array}{lllllllllllllllllllll}E & N & P & D & L & G & T & F & F & I & M & D & T & T & S & R & I & I & G & H & 300\end{array}$ gatgcaagagaagaatggcgtaaaatgatggtgtcgtaccagtgatttcgtcattacat 960 $\begin{array}{lllllllllllllllllllll}D & A & R & E & E & W & R & K & N & D * & G & V & V & P & V & I & S & S & L & H & 320\end{array}$ ccgtccaatcaaccatttgttaatgttacgaatgatgaacctgccacacgcagaggtatc 1020 $\begin{array}{llllllllllllllllllllllllll}P & S & N & Q & P & F & V & N & V & T & N & D & E & P & A & T & R & R & G & I & 340\end{array}$ tggcaagtcaaaccaatcatacaaggatgggatcatgtcgattttattggtgtggacttc 1080

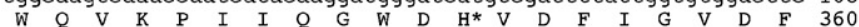
ctggatttcaaacgtaaaggtgcagaacttgccaacttctatacaggtattataaatgac 1140 $L$ D F K 380

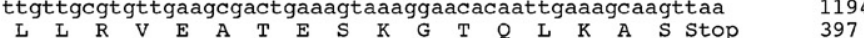

(B) $\operatorname{sXL2}_{\text {SXI1 }}$

SXL1
SAL NCTC8530
SEL3

SEL3
SHL
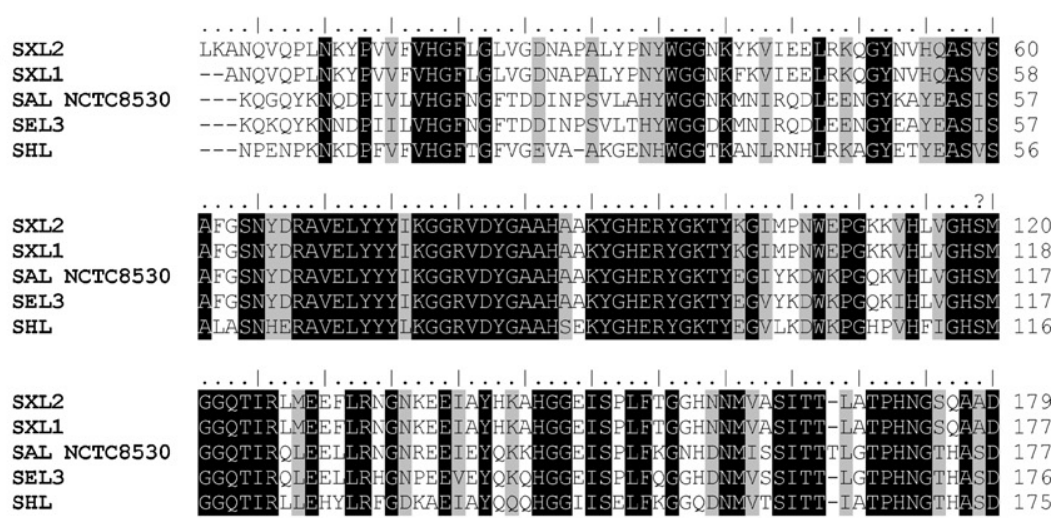

SXL2
SXL1
SAL NCTC8530
SEL3

SHL

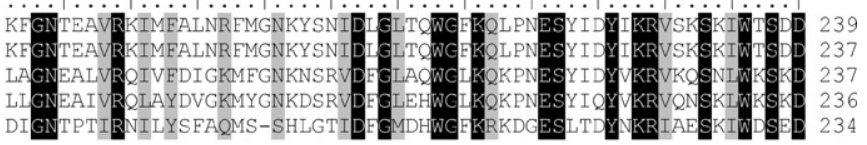

SXI2

SXI1

SAL NCTC8530

SEL3

SHL
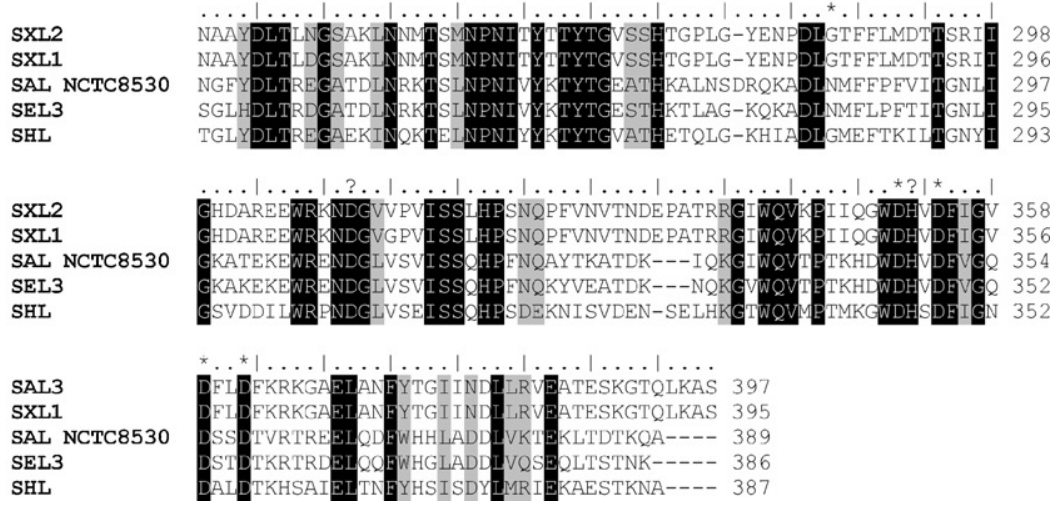

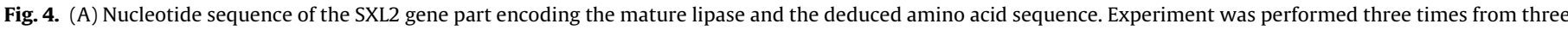

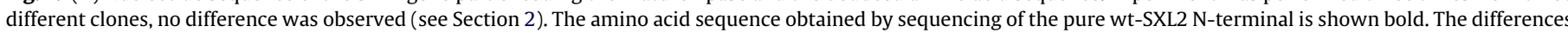

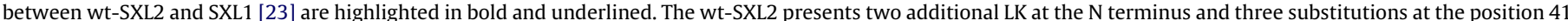

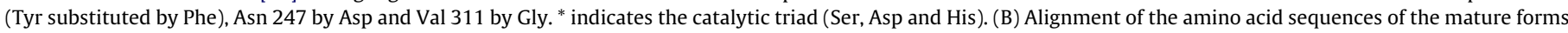

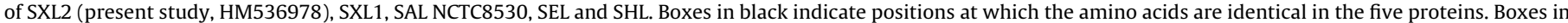

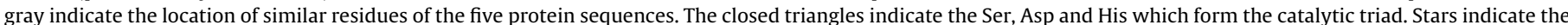
calcium-binding residues. The dashes represent gaps introduced during the alignment process. The alignment was generated with BioEdit software. 

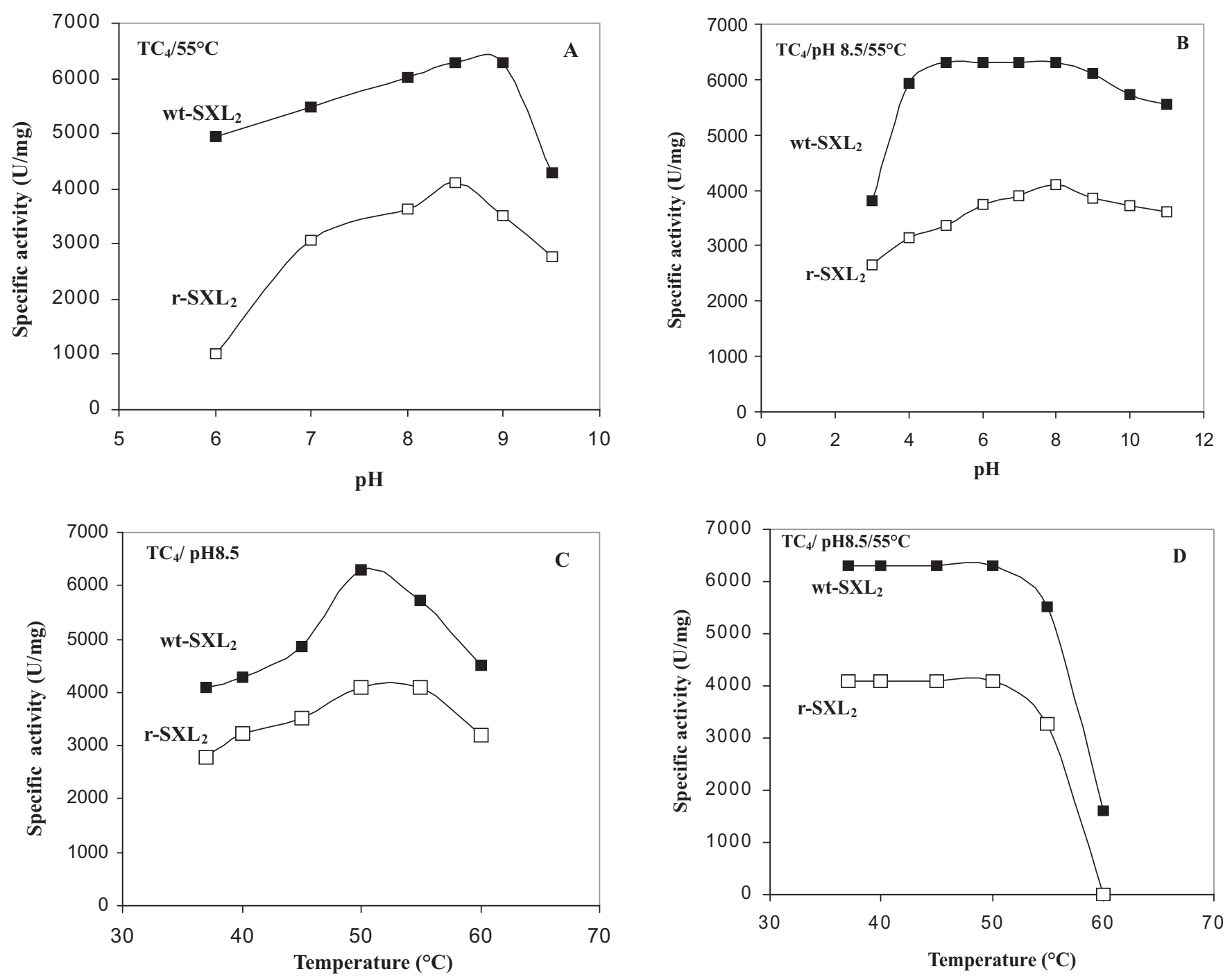

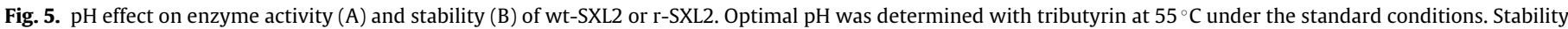

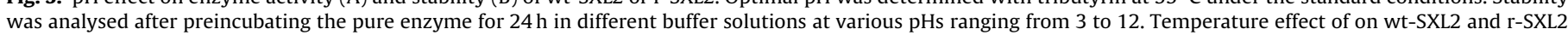

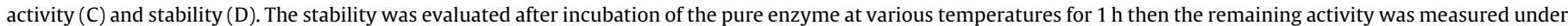
standard conditions.

\subsection{Expression and purification of the r-SXL2}

The expression of the $S$. xylosus lipase in E. coli BL21 (DE3) was carried out in the presence of different concentrations of IPTG $(0.1-0.8 \mathrm{mM})$. The initial absorbance (OD) used for the r-SXL2 and wt-SXL2 production was 0.2 . The lipase activity of r-SXL2, like the wt-SXL2, was detected to start soon after incubation and reaches its maximal $(600 \mathrm{U} / \mathrm{ml})$ at the end of the exponential phase corresponding to $10 \mathrm{~h}$ of cultivation time after induction with $0.4 \mathrm{mM}$ IPTG (data not shown). Lipase activity of r-SXL2 $(600 \mathrm{U} / \mathrm{ml})$ was approximately 3 -fold higher than that of the wt-SXL2 $(220 \mathrm{U} / \mathrm{ml})$. The difference in the activity level between the two lipases could be explained by the fact that the r-SXL2 was expressed in E. coli under the control of a strong T7 promoter which is induced by IPTG.

The purification of the r-SXL2 was facilitated by the presence of six histidine residues at the N-terminus of the enzymes. This allowed us to use only one step to purify the lipases using Ni-NTA affinity chromatography. The results of SDS-PAGE of the pooled fractions after the Ni-NTA affinity step are given in Fig. 2B. It was found that the purified recombinant lipase exhibits one band corresponding to a molecular mass of about $45 \mathrm{kDa}$. The difference of about $2 \mathrm{kDa}$ between the wild type and recombinant tagged lipase is due to the presence of the His tag extension at the $\mathrm{N}$-terminal of the mature lipase (Fig. 2B).

The purification flow sheet given in Table 1 showed that the $\mathrm{r}$ SXL2 was purified to homogeneity with a high purification yield of $67 \%$. One can note that the use of Ni-NTA gel allowed us to produce a high amount of the His tag lipase $(2.7 \mathrm{mg})$. In contrast, a lower quantity $(0.8 \mathrm{mg})$ of the pure r-SXL2 was obtained after three chromatographic steps.

Table 1 shows also that the specific activity of the r-SXL2 was $4100 \mathrm{U} / \mathrm{mg}$ or $1500 \mathrm{U} / \mathrm{mg}$ when using $\mathrm{TC}_{4}$ or olive oil emulsion as substrates, respectively. The slight decrease in the specific activity of the r-SXL2 (4100 U/mg) compared to the wt-SXL2 $(6300 \mathrm{U} / \mathrm{mg})$ is probably due to the presence of six histidine residues at the $\mathrm{N}$-terminus of the recombinant protein. Similar results were previously observed by Horchani et al. showing that the N-terminus His-tag affects the specific activity of the SAL3. The effect of the His-tag is more pronounced when using olive oil as sub- 
strate. In contrast, with a partly water soluble substrate $\left(\mathrm{TC}_{4}\right)$ this above mentioned negative effect is minimum [28,29]. In the light of the data obtained in previous study, it can be assumed that independently from the negative effects of the recombinant expression process per se, the presence of an $\mathrm{N}$-terminal tag extension decrease the catalytic activities of staphylococcal lipases by creating a steric hindrance during the interfacial binding step [28,29]. An alternative hypothesis is that the N-terminal tag extension process may be responsible for a change in the orientation of the lipase at the interface. One can also note that the wild type staphylococcal lipases are secreted into the culture medium, contrary to what occurs with the recombinant untagged or tagged lipases, which are produced in the form of intracellular proteins [14,20,24]. It has been reported that the rate of translation of a protein can affect its folding and activity. This hypothesis might therefore explain the differences observed here between secreted and intracellular staphylococcal lipases.

\subsection{Comparison of the biochemical properties of the wt-SXL2 and} the $r$-SXL2

\subsubsection{Effects of $p H$ and temperature on $w t-S X L 2$ and $r$-SXL2 activity and stability}

A great deal of research is currently going into developing lipases, which will work under thermostable and alkaline conditions as fat stain removers.

The activity of the wt-SXL2 and the r-SXL2 was investigated at different pHs using tributyrin as substrate (Fig. 5A). Results show that, the wt-SXL2 and the r-SXL2 remain active at alkaline $\mathrm{pH}$ ranging from 8 to 9.5 and their maximal activities were measured at $\mathrm{pH}$ 8.5.

To determine the pH stability, the two lipases were incubated at different $\mathrm{pHs}$ and the residual activity was determined under optimal conditions at $\mathrm{pH} 8.5$ and $55^{\circ} \mathrm{C}$. Our results show that the two lipases were stable at a broad range of $\mathrm{pH}$ values between $\mathrm{pH} 4$ and 12 after $24 \mathrm{~h}$-incubating (Fig. 5B). The activity and the stability of lipases in alkaline media are very attracting, for example, lipase produced by Acinetobacter radioresistens has an optimum $\mathrm{pH}$ of 10 and it was stable over a $\mathrm{pH}$ range of 6-10; this enzyme has a great potential for application in the detergent industry [30].

The lipase activity was also measured at different temperatures $\left(37-60^{\circ} \mathrm{C}\right)$ under standard assay conditions (Fig. 5C). One can note that the wt-SXL2 and the r-SXL2 activity increased significantly with increasing the temperature to reach its maximum value at $55^{\circ} \mathrm{C}$. The thermostability of the wt-SXL2 and the r-SXL2 was also determined by measuring the residual activity after incubation $(60 \mathrm{~min})$ of the pure lipases at various temperatures $\left(37-60^{\circ} \mathrm{C}\right)$ (Fig. 5D). The wt-SXL2 and the r-SXL2 retained 90\% of their initial activities after $60 \mathrm{~min}$ incubation at $55^{\circ} \mathrm{C}$.

Thermostable and alkaline lipases are therefore highly attractive [31] to the synthesis of biopolymers and biodiesel and used for the production of pharmaceuticals, agrochemicals, cosmetics, and flavour [32]. All these findings allow us to conclude that the wt-SXL2 and the r-SXL2 could be good candidates for industrial applications.

\subsection{Effects of bile salts on wt-SXL2 and r-SXL2}

It is well known that all detergents act as potent inhibitors of pancreatic and some microbial lipases [33]. In order to check if the purified wt-SXL2 and r-SXL2 are able to hydrolyse triacylglycerols in the presence of some surface-active agents like bile salts, the hydrolysis rate of $\mathrm{TC}_{4}$ by wt-SXL2 and r-SXL2 was measured in the presence of various NaDC concentrations. Fig. 6 shows that the maximal activity for the wt-SXL2 or r-SXL2 is reached in the presence of $2 \mathrm{mM}$ or $1 \mathrm{mM}$ of $\mathrm{NaDC}$ using tributyrin as substrate,

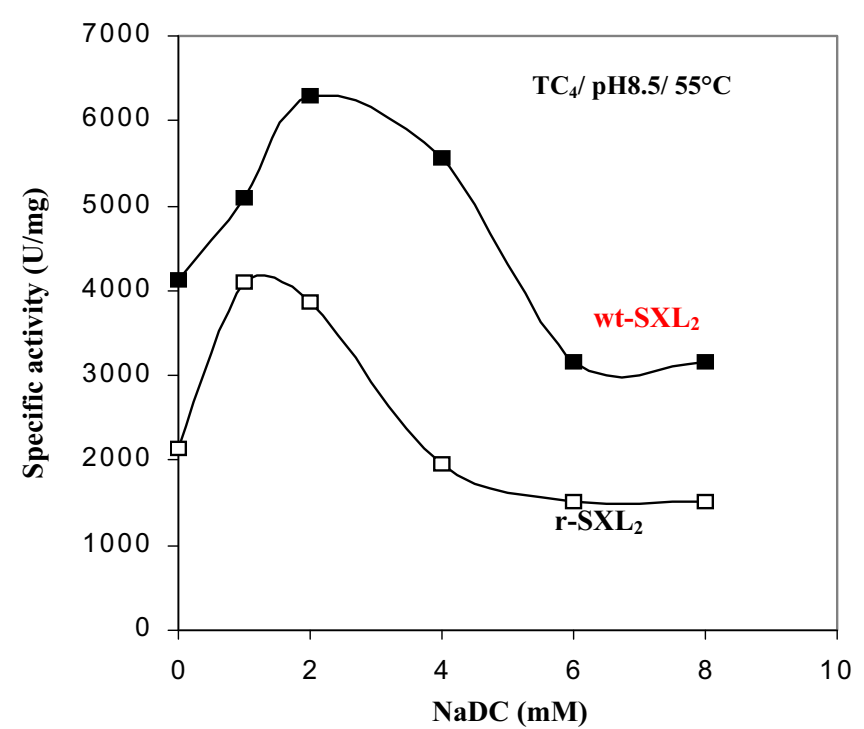

Fig. 6. Effect of increasing concentration of detergent $\operatorname{NaDC}(0,1,2,4,6,8 \mathrm{mM})$ on the hydrolysis rate of tributyrin by wt-SXL2 and r-SXL2. Lipolytic activity was measured using tributyrin as substrate at optimal conditions of each lipase at $\mathrm{pH}$ 8.5 and $55^{\circ} \mathrm{C}$. Assay conditions: tributyrin $(0.25 \mathrm{ml})$ in $30 \mathrm{ml}$ of $2.5 \mathrm{ml}$ Tris- $\mathrm{HCl}$.

respectively. This activity drops $50 \%$ down at a concentration of bile salt between 5 and $8 \mathrm{mM}$. One can note that wt-SXL2 and rSXL2 are able to hydrolyse efficiently triacylglycerols even in the presence of bile salts. Similar results were obtained with SSL [20], SXL1 [24] and SAL3 showing that these enzymes are stable at high concentrations of detergents. Hence, it can be deduced that SXL2 penetration power is higher than those of pancreatic and some microbial lipases since it can hydrolyze $\mathrm{TC}_{4}$ even in the presence of amphiphilic proteins.

\subsection{Effects of calcium on wt-SXL2 and r-SXL2 activity}

Previously, it has been demonstrated that the activity of staphylococcal lipases may depend on the presence of $\mathrm{Ca}^{2+}$ ions [4]. We therefore studied the effect of various $\mathrm{Ca}^{2+}$ concentrations on the rate of hydrolysis of wt-SXL2 and r-SXL2. Our results showed that the wt-SXL2 activity requires the presence of $\mathrm{Ca}^{2+}$ to trigger the hydrolysis of triacylglycerols. A maximum activity was obtained in the presence of $2 \mathrm{mM} \mathrm{CaCl}_{2}$ (data not shown). In contrast, the activity of the r-SXL2 can be detected in the absence of $\mathrm{Ca}^{2+}$. In fact, a specific activity of $2050 \mathrm{U} / \mathrm{mg}$ was measured in the absence of $\mathrm{Ca}^{2+}$ and in the presence of $10 \mathrm{mM}$ of chelator such as EDTA or EGTA, when using tributyrin as substrate. This result is in line with previous works showing that the enzymatic activity of staphylococcal lipases is stimulated by $\mathrm{Ca}^{2+}[4,20]$. It has been also reported that lipases from P. gluma [34] and S. hyicus [35] contain a $\mathrm{Ca}^{2+}$ binding site which is formed by two conserved aspartic acid residues near the active-site, and that the binding of the $\mathrm{Ca}^{2+}$ ion to this site dramatically enhanced the activities of these enzymes. Both residues are conserved in wt-SXL2 as well as in all other staphylococcal lipases sequences, indicating that these lipases probably bind $\mathrm{Ca}^{2+}$ at the same site [34].

\subsection{Enzymatic esterification}

Interest in the staphylococcal lipases was originally stimulated by their ability to catalyse the esterification, interesterification, and transesterification in non-aqueous media. The obtained esters are versatile components of flavours, fragrances, antioxidants which are widely used in the food, beverage, cosmetic, and pharmaceutical industries. Therefore, the ability of the newly isolated 


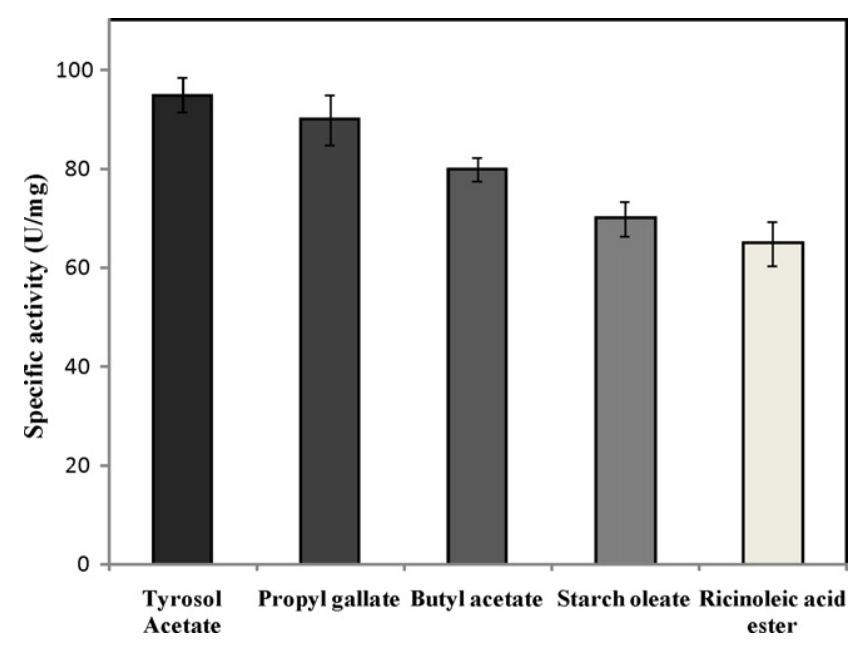

Fig. 7. Synthesis of tyrosol acetate, propyl gallte, butyl acetate, starch oleate and ricinoleic acid esters by immobilized Staphylococcus xylosus lipase (wt-SXL2).

immobilized wt-SXL2 to synthesize some esters such as propylgallate, starch oleate, butyl oleate, tyrosol acetate and ricinoleic acid esters was studied. After optimization of the conditions of the synthesis of such molecule, the conversion yields were determined at equilibrium and the results are shown in Fig. 7. One can note that the immobilized wt-SXL2 is able to synthesise antioxidants such as propyl gallate and tyrosol acetate with a high conversion yield of $90 \pm 3.5$ and $95 \pm 5 \%$, respectively. It can also be used as biocatalyst to synthesize butyl acetate (pineapple flavour) with a high conversion yield $(80 \pm 2.5)$. Others esters were also synthesized using immobilized wt-SXL2 as biocatalyst by esterification of oleic acid with starch to produce fully biodegradable thermoplastic materials ( $70 \pm 3.5 \%$ of conversion yield) and by esterifiaction of ricinoleic acid to produce ricinoleic acid esters $(65 \pm 4.5 \%$ of conversion yield). These achievements would help to save petrochemical resources and to find out new industrial uses of starches and castor oil.

\section{Conclusions}

In this study the lipase from $S$. xylosus 2 displayed encouraging properties for biotechnological applications which are different from other staphylococcal lipases. It presents a specific activity 6fold and 3-fold higher than the SSL and the SXL1. The expression of this enzyme produces a quantity of purified lipase higher than that obtained with other over-producing bacteria. Many properties of wt-SXL2 were investigated, the high stability and activity at high temperature and at alkaline conditions and the ability to synthesise a high value molecules are especially encouraged.

\section{Acknowledgments}

Thanks are due to Mr. Ayadi HAJJI for his help with English. We thank Pr. Hafedh MEJDOUB (FSS) for the sequencing of the NH2-terminale. We thank also Dr. Hafedh DHOUIB (CBS) for the identification of the strain. This work is a part of a doctoral thesis by Ahlem BOUAZIZ. Whose research was supported financially by "Ministère de l'enseignement supérieur, de la recherche scientifique et de la technologie, Tunisia" through a grant to "Laboratoire de Biochimie et de Génie Enzymatique des Lipases-ENIS".

\section{References}

[1] K.E. Jaeger, T.M. Reetz, Microbial lipases from versatile tools for biotechnology, TIBTECH 16 (1998) 396-403.
[2] A.R. Macrae, R.C. Hammond, Present and future applications of lipases, Biotechnol. Genet. Eng. Rev. 3 (1985) 193-217.

[3] J.L. Roustan, A.R. Chu, G. Moulin, F. Bigey, A novel lipase/acyltransferase from the yeast Candida albicans: expression and characterisation of the recombinant enzyme, Appl. Microbiol. Biot. 68 (2005) 203-212.

[4] R. Rosenstein, F. Götz, Staphylococcal lipases: biochemical and molecular characterization, Biochimie 82 (2000) 1005-1014.

[5] R. Gupta, N. Gupta, P. Rathi, Bacterial lipases: an overview of production, purification and biochemical properties, Appl. Microbiol. Biot. 64 (2004) 763781.

[6] S.E. Lumor, C.C. Akoh, Esterification and hydrolytic activities of Candida rugosa lipase isoform 1 (LIP1) immobilized on Celite 545, Duolite A7, and Sephadex G-25, J. Agric. Food Chem. 56 (2008) 10396-10398.

[7] K. Chakraborty, R.P. Raj, An extra-cellular alkaline metallolipase from Bacillus licheniformis MTCC 6824: purification and biochemical characterization, Food Chem. 109 (2008) 727-736.

[8] F. Hasan, A.A. Shah, A. Hameed, Industrial applications of microbial lipases, Enzyme Microb. Technol. 39 (2006) 235-251.

[9] S.H. Ha, M.N. Lan, S.H. Lee, S.M. Hwang, Y.M. Koo, Lipase-catalyzed biodiesel production from soybean oil in ionic liquids, Microb. Technol. 41 (2007) 480-483.

[10] H. Yao, S. Yu, L. Zhang, K. Zuo, H. Ling, F. Zhang, K. Tang, Isolation of a novel lipase gene from Serratia liquefaciens S33DB-1, functional expression in Pichia pastoris and its properties, Mol. Biotechnol. 38 (2008) 99107.

[11] R. Quintana-Castro, P. Diaz, G. Gerardo Valerio-Alfaro, S. Hugo, H.S. Garcia, R. Rosamaria Oliart-Ros, Gene cloning, expression, and characterization of the Geobacillus thermoleovorans CCR11 thermoalkaliphilic lipase, Mol. Biotechnol. 42 (2009) 75-83.

[12] Z. Jiang, Y. Zheng, Y. Luo, G. Wang, W. Wang, Y. Ma, D. Wei, Cloning and expression of a novel lipase gene from Pseudomonas fluorescens B52, Mol. Biotechnol. 31 (2005) 95-101.

[13] B. Lui, X. Qian, Q. Wu, X. Lin, Two lipase-catalyzed sequential synthesis of drug derivatives in organic media, Enzyme Microb. Technol. 43 (2008) 375-380.

[14] H. Horchani, H. Mosbah, N. Ben Salem, Y. Gargouri, A. Sayari, Biochemical and molecular characterisation of a thermoactive, alkaline and detergent-stable lipase from a newly isolated Staphylococcus aureus strain, J. Mol. Catal. B: Enzym. 56 (2009) 237-245.

[15] H. Horchani, M. Chaabouni, Y. Gargouri, A. Sayari, Solvent-free lipase-catalyzed synthesis of long-chain starch esters using microwave heating: optimization by response surface methodology, Carbohyd. Polym. 79 (2010) 194201.

[16] H. Horchani, N. Ben Salem, Z. Zarai, A. Sayari, Y. Gargouri, M. Chaabouni, Enzymatic synthesis of eugenol benzoate by immobilized Staphylococcus aureus lipase: optimization using response surface methodology and determination of antioxidant activity, Bioresour. Technol. 101 (2010) 28092817.

[17] A. Bouaziz, H. Horchani, N. Ben Salem, M. Chaabouni, Y. Gargouri, S. Sayari, Enzymatic propyl gallate synthesis in solvent-free system: optimization by response surface methodology, J. Mol. Catal. B: Enzym. 67 (2010) 242-250.

[18] J. Rathelot, R. Julien, P. Canioni, C. Coeroli, L. Sarda, Studies on the effect of bile salt and colipase on enzymatic lipolysis. Improved method for the determination of pancreatic lipase and colipase, Biochimie 57 (1975) 1117-1122.

[19] A. Birnboim, A rapid alkaline extraction method for the isolation of plasmid DNA, Method Enzymol. 100 (1983) 243-255.

[20] A. Sayari, N. Agrebi, S. Jaoua, Y. Gargouri, Biochemical and molecular characterization of staphylococcus simulans lipases, Biochimie 83 (2001) 863-871.

[21] U.K. Laemmli, Cleavage of structural protein during the assembly of the head of bacteriophage T4, Nature 227 (1970) 680-685.

[22] M.M. Bradford, A rapid and sensitive method for the quantitation of quantities of protein utilising the principle of protein-dye binding, Anal. Biochem. 72 (1976) 248-254.

[23] H. Bergman, T. Jörnvall, Electroblotting of individual polypeptides from SDS/polyacrylamide gels for direct sequence analysis, Eur. J. Biochem. 169 (1987) 9-12.

[24] H. Mosbah, A. Sayari, H. Mejdoub, H. Dhouib, Y. Gargouri, Biochemical and molecular characterization of Staphylococcus xylosus lipase, Biochim. Biophys. Acta 1723 (2005) 282-291.

[25] J.W. Simons, H. Adams, R.C. Cox, N. Dekker, F. Götz, A.J. Slotboom, H.M. Verheij, The lipase from Staphylococcus aureus. Expression in Escherichia coli, large-scale purification and comparison of substrate specificity to Staphylococcus hyicus lipase, Eur. J. Biochem. 242 (1996) 760-769.

[26] H. Mosbah, H. Horchani, A. Sayari, The insertion of (LK) residues at the N-terminus of Staphylococcus xylosus lipase affects its catalytic properties and its enantioselectivity, Process Biochem. 45 (2010) 777785.

[27] S. Jaeger, G. Demleitner, F. Götz, Lipase of Staphylococcus hyicus: analysis of the catalytic triad by site-directed mutagenesis, FEMS Microbiol. Lett. 79 (1992) 249-254.

[28] H. Horchani, S. Ouertani, Y. Gargouri, A. Sayari, The N-terminal His-tag and the recombination process affect the biochemical properties of Staphylococcus aureus lipase produced in Escherichia coli, J. Mol. Catal. B: Enzym. 61 (2009) 194-201.

[29] H. Horchani, L. Sabrina, L. Régine, A. Sayari, Y. Gargouri, R. Verger, Heterologous expression and $\mathrm{N}$-terminal His-tagging processes affect the catalytic properties 
of staphylococcal lipases: a monolayer study, J. Colloid Interface Sci. 350 (2010) 586-594.

[30] S.J. Chen, C.Y. Cheng, T.L. Chen, Production of an alkaline lipase by Acinetobacter radioresistens, J. Ferment. Bioeng. 86 (1998) 308-312.

[31] G.D. Haki, S.K. Rakshit, Developments in industrially important thermostable enzymes: a review, Bioresour. Technol. 89 (2003) 17-34.

[32] A. Illanes, Stability of biocatalysts, Electron. J. Biotechnol. 2 (1999) 7-15.
[33] Y. Gargouri, R. Julien, A.G. Bois, R. Verger, L. Sarda, Studies on the detergent inhibition of pancreatic lipase activity, J. Lipid Res. 24 (1983) 1336-1342.

[34] M.E.M. Noble, A. Cleasby, L.N. Johnson, M.R. Egmond, L.G.J. Frenken, FEBS Lett. 331 (1993) $123-128$

[35] J.W. Simons, M.D. van Kampen, I. Ubarretxena-Belandia, R.C. Cox, C.M. Alves dos Santos, M.R. Egmond, H.M. Verheij, Biochemistry 38 (1999) 2-10. 